\title{
Cause-Related Sports Marketing: The Role of League-Cause Fit and Team Imagery in Advertising Promotions: Abstract
}

\author{
Bridget Satinover Nichols, Joe Cobbs, and David Raska
}

\begin{abstract}
Social involvement research in the sport industry is still evolving, leaving much to be understood regarding the social activities of sport organizations (Walker and Parent 2010). While research suggests that CRM can positively affect purchase intentions and behavioral responses (e.g., Bhattacharya and Sen 2003), the rise in CRM activities in professional sports and the breadth of philanthropic partners among individual leagues warrants a deeper understanding of how and when sports fans respond favorably, and perhaps more importantly, unfavorably, to such initiatives.

This paper examines the role of league-cause fit, perceived sincerity, and intentions to support league-wide cause-related sports marketing efforts (CRSM). Applying the tenets of attribution theory and social identity theory, we demonstrate the potential backlash effect of using "hometown" team imagery in league-wide CRSM advertising campaigns. The results of two experiments suggest that fans exposed to a CRSM advertising campaign that portrays their hometown team perceive such efforts as less sincere, which results in lower support of league-wide efforts when compared to fans exposed to the same campaign but featuring a rival team or no specific team.

Although sports fans are often strongly attached to their favorite teams, and favor sponsor messages that are connected to their team in some way, this study provides some initial support for resisting the use of team allegiances to promote league-wide cause efforts. Importantly, when league-cause fit is low in CRSM, marketers cannot rely on favorite team imagery in ads to influence fans' intentions to support the cause. However, when league-cause fit is high, team imagery has a pronounced effect. We speculate that images of the hometown team increased attention to the ad, and increased cognitive processing of the cause message.
\end{abstract}

References Available Upon Request.

B.S. Nichols $(\varangle) \bullet J$. Cobbs $\bullet$ D. Raska

Northern Kentucky University, Newport, KY, USA

e-mail: nicholsb1@nku.edu; cobbsj1@nku.edu; raskad1@nku.edu 